\title{
The legal mechanism of bringing to account in the epoch of digitalization
}

\author{
Tatiana Deryugina*1, Lyudmila Chegovadze $^{2}$, Albert Tumakov ${ }^{3}$ and Felix Vertlib ${ }^{4}$ \\ ${ }^{1}$ Kikot Moscow University of the Ministry of Internal Affairs of Russia, st. Academician Volgina, 12, Moscow, Russia, \\ sofija96@mail.ru \\ ${ }^{2}$ Kikot Moscow University of the Ministry of Internal Affairs of Russia, st. Academician Volgina, 12, Moscow, Russia, \\ chegov@mail.ru \\ ${ }^{3}$ Kikot Moscow University of the Ministry of Internal Affairs of Russia, st. Academician Volgina, 12, Moscow, Russia, albert- \\ tumakov@rambler.ru \\ ${ }^{4}$ Kikot Moscow University of the Ministry of Internal Affairs of Russia, st. Academician Volgina, 12, Moscow, Russia, \\ vertlib.f@gmail.com
}

\begin{abstract}
An analysis of problems occurring during the application of civil liability in legal relationships using information and communication technologies is being conducted in this scientific research. Apart from the absence of legal norms, there are conflict-of-laws rules, contradictions in which are to be resolved. The research of the turnover using digital technologies takes a big part in the legal doctrine. It must be noted that several fundamental works have appeared that make it possible to create a harmonious and non-contradictory system of legal regulation. However, there are still some unresolved questions left; for instance, ones concerning the mechanism of legal regulation of civil liability of subjects that have entered relations using digital technologies. The analysis of the civil law doctrine, the propositions of current Russian and international legislations, and legal practice have revealed a complex of problems connected to the civil liability of subjects entering legal relations using information and communication technologies. It became possible to systemize them depending on the subject and their role in the initiation or termination of the relation. A range of methods (general, general scientific and legal) has made it possible to make conclusions about the reasons why legal regulation is imperfect and why conflicts exist (to prevent them from happening in the future), formulate a legal regime of liability of subjects of the main or supporting group, suggest alterations to the current Russian legislation, aimed at bringing the owner of the information system to account.
\end{abstract}

\section{Introduction}

The development of digital technologies positively influences various spheres of society, including the ones connected to entering legal relations. Fast and expensewise economical deal conclusion using digital information systems, document exchange, submission of claims, the possibility to access big information volumes - all this makes communication of significantly easier and finally increases the efficiency of economic activity. However, the negative sides of these processes cannot be ignored.

After the introduction of information and communication technologies the condition of protection of the individual and the society from informational threats requires particular attention of the state. This in turn requires the development of new means of legal guarding and protection of subjective rights and the interests of the subjects of legal relations. Despite the numerous researches aimed at addressing the questions of legal regulation of relations connected to using the digital environment, bridging the gaps and solving conflicts, which have appeared in the law field in the last five years, a lot of problems remain unresolved. The problem of improving the legal mechanism of bringing to account is among them.

The problems listed can be divided into two groups: ones caused by flaws in the legal regulation of relations appearing with the help of digital technologies and ones connected to the low awareness level of subjects on the peculiarities of using information and communication technologies in entering legal relations, and peculiarities of legal regulation of such relations and the protection of violated rights and rules. In order to achieve a positive result and the required effect, the problems of both groups should be solved. Forming new legal mechanism and perfecting the existing ones including those from the field of bringing to account is one of the priority areas of development of institutes and branches of law, while

\footnotetext{
*Corresponding author: sofija96@mail.ru
} 
creating a fundamental basis for effective regulation of relation is a primary objective of science.

Thus, the absence or divergence of legal rules regulating civil liability upon entering relations using information and communication technologies, the imperfection of mechanisms and procedures of their application that take the peculiarities of digital relations into account, predetermines the necessity of conducting the present research.

\section{Problem Statement}

The problems of civil liability that occur due to the use of digital technologies are of a multidimensional nature, which was mentioned on several occasions both in the Russian legal [1] science, as well as in civics [2-4] and the foreign one [5-7]. The questions of liability in the digital technology development epoch go beyond one branch of law, a set of problems appears at the intersection of different branches, which requires a multidisciplinary approach.

For instance, along with problems of civil character connected to the identification of a contract's subject, determining the place of an agreement's conclusion, determining the liability subject in entering relations using an aggregator, etc., the questions of protection of personal data of a contract's subjects, the protection of confidential information, etc. are of great importance. Therefore, it is necessary to address adjacent sciences of informational, labour, constitutional, criminal law, as well as the legal theory.

Solving the problems of civil liability of subjects entering relations using digital resources is complicated by the multiplicity of subjects. Apart from the traditional contract sides, there are following subjects that can participate or influence the sides: the owner of the information resource used to enter the relations (generally aggregators); the right holder of exclusive rights on the result of intellectual activity - software used by the sides to enter the relations. What is more, some authors think that the owners of technical means of information networks (technological platforms, Internet services, etc.) are subjects of the relationships as well [8]. However, the former can directly influence not only the possibility to conclude contracts, but their execution as well.

For instance, in early March 2020 a hosting provider "Masterhost" has stopped working; among its clients there are SPA "Energomash" and others [9]. The reason for the failure was the owner blocking the technical equipment after a conflict with the provider. As a result, the users of the hosting provider could not access their electronic resources for a week, which had a direct impact on their economic activity.

Undoubtedly, such events should be qualified as force majeure that exempt the sides from liability, when deciding on bringing the sides to account using the resource. However, this example illustrates the possibility of influence by a third party and their actions on realizing the rights and fulfilling the duties in legal relations that use information and communication technologies and the Internet.

Two groups of subjects should be distinguished upon reviewing the subjects of civil legal relations that appear using digital resources. The first group (let us call them main subjects) are the persons who directly conclude contracts, address claims to each other, etc. Relations between the subjects are sufficiently regulated by civil law.

However, the peculiarities of relations initiated using information and communication technologies cause the presence of another group of subjects (let us call them the supporting subjects). They are the subjects that provide mediation (generally not of legal character) connected to providing an Internet resource for the sides to communicate; for instance, the aggregators of Internet trade, information aggregators [10], authors of software, persons in possession of information, equipment owners. Even though they do not directly participate in the relations, they cannot be called a passive side. Moreover, they are given authority and are able to influence the possibility for the main participants to enter the relations. For instance, an electronic commerce aggregator has a right to restrict access to electronic resources [11], information aggregator can store and transfer information that can influence the conclusion of contracts, or their alteration and annulation, allow or restrict access to it, etc.

It follows from all the above that the existence of diverse legal subjects, their ability to influence the initiation and termination of legal relations using digital technologies is in direct correlation with the necessity to solve questions of civil liability of the subjects for breach of obligations. The crucial question is the correlation of liability of one or other of the subjects of legal relations with their role in the relation, which will allow distributing liability depending on the influence of the subject on adverse effect.

\section{Research Questions}

The emergence of digital technologies and their introduction to the economic trade creates new interdisciplinary tasks for Russian (and world) science. They can be solved by conducting research of various legal phenomena, including the legal mechanism of bringing to account and its transformation during the epoch of formation of the digital ecosystem.

In order to achieve the purpose of the study, it is necessary to consistently and systematically solve a number of theoretical and practical questions; for instance, to analyse the present Russian and foreign doctrines; to study the legal framework of the question determining the set of problems connected to mechanisms of bringing to account the subjects entering the trade using information systems, to review the practice of application of the existing rules of law in order to identify questions that have to be regulated by the rules of law, to solve existing conflicts, to systemize the problems identified and suggest ways to solve them based on the conducted research. 


\section{Purpose of the Study}

The present study is aimed at the fundamental development and scientific reasoning of solving problems connected to legal mechanisms of bringing to account in the epoch of formation of the digital ecosystem, subjects entering legal relations using information and communication technologies. The scientific positions developed will become a base for the creation of adequate modern legal constructions meeting the requirements of the digital economy and for further improvement of the actual legislation.

\section{Research Methods}

While conducting the research the authors relied upon (1) common scientific methods (dialectical, system approach), which allowed to examine the mechanism of liability of persons entering relations using information and communication technologies as a united system of legal rules, establish a connection and intersectionality of the processes; (2) general scientific methods (analysis and synthesis, systemic functional method, induction, deduction, analogy, modelling) that made it possible to establish particular elements of the content of legal categories, discover general patterns of liability in the digital age, establish the influence of separate factors on the development of a relation; (3) specifically legal methods (dogmatic, comparative legal, legal prediction) that made it possible to identify formal logical connections, formulate perspectives of legal regulation of relations connected to civil liability of subjects in the digitalization epoch.

\section{Findings}

Various sources in the scientific literature are dedicated to the question of civil liability, the liability in the age of digitalization included, both Russian [12, 13] and foreign [14-16]. The problems specified in the scientific literature can be divided into two groups: ones concerning main subjects of legal relations (subjects of contract, transaction, etc.) and ones concerning subjects performing supporting functions (non-legal mediators: owners of digital networks, websites and other kinds of information infrastructure).

Among the problems of main subjects that require immediate solution there are problems of identification of the subject entering legal relations using information and communication technologies; the problem of the national treatment (the law that will be applied to the relations); the problem of determining the scene of a legally important action (the transfer of goods, the payment, etc.)

As for the problems of subjects of the supporting group, the main place is taken by the problem of their influence on the initiation, alteration and termination of relations between main subjects and, consequently, the possibility of bringing them to account in cases when they are not among the sides of the principal obligation. And here, perhaps, the question of the legal nature of relations between the owners of Internet services, websites and information systems becomes the most important.

For instance, considering a case on causing death as a result of a car accident by a taxi service, the first and the second instances have rejected the claim to the information aggregator ("Taxi Prestige" LLC) through the services of which the order was made, pointing at the circumstance that the sides (the carrier and the passenger) have concluded the contract of transportation, of which the "Taxi Prestige" LLC is not a side and, consequently, is not responsible for it. Only the Supreme court of the Russian Federation has qualified the actions of the aggregator as these of an agent, pointing at the responsibility of the agent according to article 1005 of the Civil code of the Russian Federation [17]. In another case, where the question of the possibility of bringing an aggregator into account on the contract of transportation was discussed, the court has qualified the relations of the aggregator and the carrier as organizational, pointing that since the aggregator creates the conditions for the transportation, they take part in the activity that creates high risks. Consequently, they can be brought to account [18].

The question of bringing to account the owners of infrastructure (subjects of supporting group) is directly connected to the recent discussion of whether it is possible for artificial intelligence to be a subject of law. In this case the opinions differ from positions stating the necessity to bring its developer to account or its user to bringing to account the intelligence itself [19-22].

Unfortunately, it is to be stated that despite the rapid development of economy using information and communication technologies, civil regulation of such relations falls behind significantly. The most advanced one is the consumer protection legislation that implies mutual rights and obligations of the aggregator's owner, the executor, the seller, as well as the liability of the owner for improper information on the goods [23].

Among recent alterations of the legislation aimed at introducing digital technologies there are the emergence of digital law as a subject of civil rights (article 128 of the Civil code of the Russian Federation), the right to vote at a meeting using electronic or technical means (article 181.2 of the Civil code of the Russian Federation), the possibility for the sides of an obligation to execute it using information technologies determined by the terms of the contract (article 309 of the Civil code of the Russia Federation), the possibility to compose a contract in electronic form and the possibility to exchange electronic documents (article 434 of the Civil code of the Russian Federation), the possibility of purchase of digital rights (article 454 of the Civil code), formulating the features of the information provision contract (article 783.1 of the Civil code), the introduction of liability for the information mediator exclusively for intellectual rights (article 1253.1 of the Civil code of the Russian Federation) and others [24]. Apart from this, the concept of utilitarian digital rights was introduced to the legislation, as well as the legal regulation of the utilitarian digital rights turnover on investment platforms that are information systems [25]. 
Among positive aspects of civil liability regulation there are: (1) the appearance of the liability of investment platforms operators, news aggregators, search systems operators, owners of audio-visual services, information mediators (for intellectual rights), which demonstrates the focus of the legislator on the possibility of applying sanctions to the subjects of the supporting group and (2) determining the law nature of the contract with an aggregator as a services contract. In this case there is a claim to the legislator on the imperfection of major contract terms, which also negatively influences the possibility to bring the actor to account.

As for the negative aspects, they are: (1) the possibility of establishing the content of a digital right and the rules of its realization by the information system operator without determining the system of restrictions and limits in the legislation, which, due to a faulty formulation of the article 141.1 of the Civil code of the Russian Federation that does not list property rights included in the digital right, can make the body applying the law think that the content of property right can be established not only by the law but by the information network operator as well; (2) the presence of gaps in the law, including questions of civil liability. The legislator has not established the content of digital law (and has not determined its borders), which makes it impossible to develop general dispositions of bringing law subjects to account; (3) the absence of unified terminology used without consideration of the dispositions of the Federal law (2006) on information, information technologies and the protection of information [26]; (4) the unsystematic attempts to regulate particular kinds of liability of information mediators (news aggregators, search system operators, owners of audio-visual services (Federal law (2006) on information, information technologies and the protection of information), investment platform operators (Federal Law (2019) on attracting investments using investment platforms and on altering the legislation of the Russian Federation). It is necessary to solve general questions of civil liability of the information system operators, and then regulate particular kinds of liability.

Addressing the international statutes, one can note their focus on bringing to account (in case of offense) all subjects of both main and supporting groups. For instance, in the European Parliament resolution of 16 February 2017 with recommendations to the Commission on Civil Law Rules on Robotics[27] the necessity to bring to account the manufacturers, users, operators and owners of networks is noted. The liability must accrue without guilt. What is more, it is specified in the act that it is impossible to dismiss bringing to account based on the fact that the damage was caused not by a human (which seems to suggest that the European parliament is in favour of the possibility of bringing artificial intelligence). Undoubtedly, the rules of liability mentioned mostly concern artificial intelligence, though the main idea is that all involved must be brought to account.

It must be noted that in the developed draft of the Federal law "On altering the Civil code of the Russian
Federation in perfecting the legal regulation of relations in the field of robotics" the necessity to bring to account both the owner and the owner of the robot-agent was noted. In our opinion, the great advantage of the draft law was the definition of the nature of arising relations.

The analysis conducted demonstrates the presence of systemic problems of legal regulation that can be determined as (1) problems connected to flaws in legal regulations; (2) the absence of systemic approach; (3) the inconsistency of the legislator, also in conceptual framework; (4) no solution to the principal question of the composition of the subjects of civil liability.

\section{Conclusion}

The research conducted has made it possible to formulate several scientific inferences and to develop recommendations on improving the existing legislation.

Presently the improvement of legal regulation follows the path of establishing the specificity of civil liability for some subjects of legal relations (news aggregators, information mediators, search system owners and others) that arise using information and communication technologies, which is not entirely right considering the diversity of subjects. The institute of civil liability is filled with contradicting rules with such an approach, which is unacceptable. What is more, some of the questions of liability are out of legal regulation. It is necessary to regulate general questions of liability of subjects participating in relations using information and communication technologies and determine the specificity of liability for particular participants of the market afterwards, based on this.

The subjects participating in civil legal relations using information and communication technologies are to be divided into two groups depending on the rights and obligations that influence the rise or alteration of the relation. They are the first group (main subjects), persons that directly conclude contracts, address claims, etc.; the second group (supporting subjects), the subjects that act as mediators (generally not of legal character) connected to providing resources on the Internet for the sides to communicate (for instance, Internet trade aggregators, information aggregators), the authors of software, the holders of information, search system owners, equipment owners.

The civil liability of the subjects of the supporting groups must directly correspond to their role in the legal relation risen, which will make it possible to spread the liability depending on the influence of the subject on the occurrence of negative consequences.

The creditor and the debtor (the main group of subjects) and the information system operator (the supporting group) must be the subjects of civil liability in rising relations using information and communication technologies.

It must be secured at the legislative level that the information system operators are prohibited from restricting the kinds and the volume of reparation, restrict the forms of compensation in cases when digital rights serve as civil law objects. 
When determining the legal regulation of civil liability of subjects entering legal relations using information and communication technologies, a legal construction consisting of two contracts must be used: the services contract concluded by the consumer and the information system operator and a services contract with the information system operator and the executor as sides.

The condition of the obligatory execution of the contract in favour of an undefined group of persons must be a significant term of services contract concluded between the information system operator and the executor.

The subsidiary liability of the information system operator and the executor (the contactor, the seller) must be determined at the legislative level.

\section{References}

1. V.N. Lopatin, Information law, 2, 14 - 19. (2018)

2. E.A. Abrosimova, The organizers of trade: the legal status and functional purpose [Dissertation of Doctor of Law]. (Moscow, Russia: Lomonosov Moscow State University, 2014).

3. A., Inshakova, E. Inshakova, A. Ryzhenkov \& M. Sevostyanov Proceedings of the International Scientific Conference in Memory of Oleg Inshakov (1952-2018)), 421-429 (2020).

4. A.E. Molotnikov \& E.V. Arkhipov, Entrepreneurial law, 4, 38-47, (2017)

5. C. Bublitz, A. Wolkenstein, R.J Jox \& O. Friedrich, International Journal of Law and Psychiatry, 65, 101-123 (2019)

6. P. Čerka, J. Grigienè, \& G. Sirbikytè, Computer Law \& Security Review, 31, 376-389 (2015).

7. W. Huang \& X. Li, Computer Law \& Security Review, 35, 105-112 (2019)

8. V.N. Lopatin, Information law, 2(33), 10 - 13 (2013).

9. D. Shestoperov, H. Aminov, N. Schurenkov, \& E. Volkova, Kommersant, 39, 10-13 (2020)

10. State Duma of the Russian Federation. (2006a). The Civil code of the Russian Federation (part four). (December 18, 2006 No 230-FL; edition of 26 July 2019)

11. The government of the Russian Federation. The order "On creating a united trade aggregator" (April 28, 2018 No 824-p.)

12. V.V. Arkhipov, \& V.B. Naumov, Zakon, 5, 159170 (2017)

13. V.B. Nagrodskaya, New technologies (blockchain / artificial intelligence) at the service of law: a methodological teaching aid (Moscow: Prospect, 2019).

14. L. Darrell, \& Ph. D Ross, Civil Liability in Criminal Justice, 5, 1-22 (2009)
15. J. Klick, \& J. MacDonald, International Review of Law and Economics, 63, 105-112 (2020)

16. B. Turvey, Forensic Victimology, 2, 429-455(2014)

17. The Supreme court of the Russian Federation. The determination of 9 January 2018 No 5-CC 17-220. Moscow, the Russian Federation (2018)

18. The Supreme court of the Tatarstan Republic. The ruling of appeal of 5 May 2016 on case No 338017/2016. Kazan, the Russian Federation (2016)

19. V.V., Arkhipov, \& V.B. Naumov, SPIIRAS Proceedings, 6, 46-62 (2019).

20. Daar, J. The Legal Liability Landscape and the Person/Property Divid. URL: https://reader.elsevier.com/reader/sd/pii/S26663341 20300519?token=16A3DD4D2D1796C496AB8AD 5A76213184B4AB105B7046BA58DDBFA46AD7 6F8A7C2CBA0398C8413ADAC2045EDC6ECE78 7 (date of access: 17.03.2021)

21. V.A. Laptev, Pravo. Zhurnal Vysshey Shkoly Ekonomiki, 2, 79-102 (2020).

22. P.M. Morhart, Artificial Intelligence: the legal perspective. (Moscow, Buki Vedi. 2017).

23. State Duma of the Russian Federation. The law of the Russian Federation "On the protection of consumers' rights" (February 07, 1992 No 2300-1, edition of 24 April 2020)

24. State Duma of the Russian Federation. The Federal law "On the alteration to parts one, two and the article 1124 of part three of the Civil code of the Russian Federation" (March 03, 2019 No 34-FL)

25. State Duma of the Russian FederationThe Federal law "On attracting investments using investment platforms and on altering some rules of the legislation of the Russian Federation" (August 02, 2019 No 259-FL, edition of July 20, 2020)

26. State Duma of the Russian Federation. The Federal law "On information, information technologies and information protection" (July 27, 2006 No 149-FL, edition of April 03, 2020)

27. The European parliament. "Civil Law Rules on Robotics” resolutions (Strasbourg, Switzerland. February 16, 2017) 